\title{
BARQUEIROS, NAVEGAÇÃO E CULTURA: \\ NARRATIVAS E REPRESENTAÇÕES ACERCA DA DOMINAÇÃO E DAS RESISTÊNCIAS NAS ÁGUAS DOS RIOS ARAGUAIA E TOCANTINS ENTRE OS SÉCULOS XIX E XX
}

\author{
BOATERS, NAVIGATION AND CULTURE: \\ NARRATIVES AND REPRESENTATIONS OF DOMINATION AND RESISTANCE WATERS OF

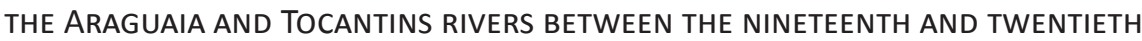 \\ CENTURIES.
}

\author{
Euclides Antunes Medeiros* \\ euclides.antunes@uol.com.br \\ Olívia Macedo Miranda Cormineiro** \\ oliviacormineiro@uol.com.br
}

RESUMO: Neste artigo pretendemos perscrutar as representações construídas pelas narrativas do médico Francisco Ayres da Silva e outros interlocutores relativas aos sertões que são singrados pelos rios Araguaia e Tocantins e que circunscrevem os Estados de Pará, Maranhão e norte de Goiás, atual Estado de Tocantins ${ }^{3}$. Interrogando essas narrativas pretendemos evidenciar algumas das dimensões socioculturais que envolvem o trabalho e a vida das tripulações que navegavam esses rios entre as últimas décadas do século XIX e as primeiras do século XX, e que, em um movimento duplo, disputavam seus modos de viver e resistiam às práticas de dominação a que eram submetidos no universo da navegação.

* Doutor pela Universidade Federal de Uberlândia. Professor Adjunto dos Cursos de História da Universidade Federal do Tocantins e do Programa de Pós-graduação em Ensino de História-PPGHIST. Líder do Grupo de Pesquisa História Regional: memórias e territorialidades.

** Doutoranda pela Universidade Federal de Uberlândia. Professora dos Cursos de História da Universidade Federal do Tocantins. Membro do Grupo de Pesquisa História Regional: memórias e territorialidades

Euclides Antunes Medeiros | Olívia Macedo Miranda Cormineiro BARQUEIROS, NAVEGAÇÃO E CULTURA 
PALAVRAS-ChAVE: Barqueiros, Dominação, Resistência.

ABSTRACT: This article aims to scrutinize the representations constructed by narratives of medical Francisco Ayres da Silva and other partners in the hinterlands that are singrados Tocantins and Araguaia Rivers by circumscribing the states of Pará, Maranhão and northern Goias, current state of Tocantins. Interrogating these narratives aim to highlight some of the socio-cultural dimensions involving the work and life of the crews that sailed these rivers and a double movement and fought her way of living and resisted the practices of domination to which they were subjected in the world of navigation between the last decades of the nineteenth century and early twentieth century.

KEY-WORDS: Boaters, Domination, Resistance.

Os rios Araguaia e Tocantins ${ }^{4}$ foram, por mais de dois séculos, os portões de acesso à Amazônia, tornando-se importante para região não apenas como via de comunicação e interesse econômico, mas também como espaços de construção sociocultural, espaços nos quais os barqueiros se constituíram importantes representantes e tradutores das experiências de viver dos e pelos rios. Denominados barqueiros ${ }^{5}$, tripulantes e remeiros, estes trabalhadores livres moviam com remos e faias os barcos e batelões que transportavam mercadorias, matérias-primas e valores culturais; contudo, ainda são homens invisíveis na historiografia. Muitas vezes, apenas uma sombra por entre os interesses econômicos dos comerciantes e donos de embarcações que faziam o percurso entre Porto Nacional, norte de Goiás, e Belém do Pará, estes (in)visíveis barqueiros têm suas imagens constituídas entre a folclorização e a estigmatização. 
Quanto à estigmatização, este não é um processo circunscrito aos barqueiros do Tocantins. Zanoni Neves, em estudo sobre as representações literárias dos remeiros do rio São Francisco, escreve:

Alguns termos e expressões - presentes em entrevistas - eram utilizados pela sociedade majoritária para discriminá-los: porco d'água, pé pubo, piau, pé de prancha, burro d'água, bicho d'água etc. Estes vocativos e epítetos partiam do barranco, do cais e dos vapores em direção às barcas. Em sentido contrário, espoucavam os palavrões visando, sobretudo, a mãe do interlocutor. Se houvesse oportunidade, a violência não ficava limitada em nível apenas verbal (NEVES, 2003, p. 179 - ênfase no original).

As evocações de uma violência simbólica contra os remeiros do rio São Francisco, presentes nas entrevistas com os ribeirinhos realizadas por Neves na década de 1990, são registros de uma longa tradição que tem cumprido o papel de opacizar a importância dos trabalhadores livres e pobres do sertão enquanto sujeitos que constituem uma ambiência cultural relevante na formação regional. Por outro lado, os poucos estudos que se referem aos barqueiros dos rios Tocantins e Araguaia estão, de certa forma, organizados dentro de uma hierarquia que subordinam a presença destes trabalhadores ora aos registros históricos das cidades ribeirinhas, que reforçam as representações destes sujeitos como parte do folclore ribeirinho, ora aos estudos históricos, que privilegiam a navegação e os aspectos econômicos da navegação dos referidos rios. Esse é o caso dos trabalhos de Dalísia Elisabeth Martins Doles e Durval Rosa Borges.

$\mathrm{Na}$ obra As comunicações Fluviais pelo Tocantins e Araguaia no século XIX, de Dalísia Elisabeth Martins Doles, publicada em 1973, que discorre sobre os rios, especialmente sobre o Tocantins, há a sugestão de que o "problema antigo da navegação" seria em parte ocasionado pela falta de disciplina dos barqueiros que atuavam nos rios Tocantins (DOLES, 1972, p. 15). O Tocantins se resume, sob a ótica desta autora, a uma via de comunicação que, repleta de obstáculos naturais, impedia o desenvolvimento da província 
de Goiás. Na visão de Doles, os barqueiros são parte do problema que dificulta o progresso da navegação, conforme registrado no relatório de província por ela citado:

De tal gravidade se revestia o problema, que em 1850, o presidente de Goiás, no seu relatório dizia: Fora longo referir-vos quanto sofre um pobre homem [o patrão ou dono do barco], que empreende a navegação do Pará. Para não perder as monções, de viagem, para não ver barcos alegados, ou abandonados, se coloca na dura necessidade de obedecerem ao menor aceno dos camaradas [barqueiros e remeiros], de aturar suas injustas pretensões. Este estado de coisas reclama providências do Corpo Legislativo Provincial. Cumpre não somente regular a disciplina, que se deve manter à (sic) bordo das embarcações, como também definir obrigações dos camaradas e patrões e cercar de garantias os contratos, que entre si estipulam. E para que se evite de futuro a duplicata de ajustes, fora conveniente abrirem-se nas subdelegacias, ou Juízes de Paz dos diversos portos do [rio] Tocantins Registros, aonde fossem obrigados a matricular-se todos os camaradas, ficando vedado à toda e qualquer pessoa fazer ajuste com aqueles que já estivessem contratados (DOLES, 1973, p. 67).

Neste trecho é possível ver que os barqueiros surgem no discurso apenas como instrumentos da navegação do Tocantins, instrumentos que, diga-se de passagem, necessitam ser controlados e ordenados. A legislação preconizada pelo Relatório do Governo da Província de Goiás foi de fato criada em vinte de julho de 1892 - Lei no 11 de Locação de Serviços -, e ficou mais conhecida como Lei da Camaradagem ${ }^{6}$. Contudo, tal lei jamais foi praticada na navegação daquele rio e esta continuou sendo feita por meio dos arranjos culturais, nos quais predominavam a exploração e a dominação, cuja luta contra ambas era a única regra aceita.

Publicado em 1987, Rio Araguaia: Corpo e Alma, do historiador Durval Rosa Borges, como o próprio nome esclarece, trata do rio Araguaia, e o subtítulo sugestivo, corpo e alma, nos levou a procurar neste trabalho algumas indicações de como a cultura do rio e, talvez, a do barqueiro, poderia surgir. Todavia, essa obra cujo foco é o "rio em sua humanidade", título de 
um dos capítulos, não inclui os barqueiros, mas somente personalidades políticas, cientistas, viajantes e exploradores, que são denominados pelo autor como amantes do rio.

Um trabalho mais recente é o da historiadora goiana Maria de Fátima Oliveira, Portos do sertão: cidades ribeirinhas do Rio Tocantins, publicado em 2010. Neste trabalho, Oliveira busca reconstruir uma identidade ribeirinha a partir do surgimento das cidades ao longo do rio Tocantins, em sua parte pertencente ao norte de Goiás. Os barqueiros são retratados sob a ótica da construção de uma identidade que, por se colocar como identificação do homem do norte, se constitui como ponto de articulação entre a identidade tocantina e a identidade tocantinense, constituída após a criação do Estado de Tocantins. Quanto à reconstrução das representações dos barqueiros, Oliveira é pontual ao afirmar:

A contradição na valoração do remador é bem visível nos documentos sobre o rio Tocantins: às vezes ele aparece como um trabalhador competente, quase herói, por exemplo, quando salva o barco, passageiros e mercadorias na travessia das cachoeiras; em outras aparece como o preguiçoso e encrenqueiro (OLIVEIRA, 2010, p. 65).

A observação de Oliveira acerca da existência de uma contradição quanto às representações feitas dos barqueiros é pertinente, pois os olhares sobre os barqueiros são de fato controversos. Todavia, preferimos historicizar estes aspectos de contradição como uma dimensão da ambivalência dos signos sociais segundo os quais os barqueiros são representados para, a partir desse ponto, buscar compreender as paisagens dessa cultura que se constitui na interface de visões algumas vezes dicotômicas e outras vezes plurivalentes. Entender essas visões relativas aos barqueiros e, consequentemente, acerca das experiências de viver nos rios Tocantins/Araguaia e dos rios Tocantins/ Araguaia como múltiplas e dialógicas aponta para um caminho historiográfico em que a busca por compreender a cultura dos grupos sociais pressupõe trabalhar com diferentes visões de mundo e olhares para o mundo. Olhares 
estes que exigem do pesquisador determinada sofisticação para entender que:

O dialógico enfatiza os termos variáveis do antagonismo, a intersecção entre diferentes 'valências' no mesmo terreno discursivo, em vez das bifurcações da dialética [que enfatiza apenas a dicotomia]. O dialógico expõe rigorosamente a falta de garantia de uma lógica ou 'lei' para o jogo da significação, os posicionamentos infinitamente variáveis dos locais em contraste com as posições dadas de antagonismo de classe, concebidas de forma clássica (HALL, 2008, p. 220).

Partindo da concepção de Stuart Hall, pretendemos problematizar a narrativa de Francisco Ayres da Silva, observando, de um lado, os múltiplos diálogos possíveis com outros viajantes que narraram os rios Tocantins e Araguaia no período e, de outro, que no interior da narrativa de Ayres e de outros viajantes se apresentam também as vozes dos barqueiros que, em um terreno comum de disputas, constituem-se também sujeitos de uma prática discursiva pautada na multivocalidade e naquilo que Mikhail Bakhtin denominou de fala não publicada. Nas próprias palavras do autor russo:

É como se as palavras fossem liberadas dos grilhões do sentido [préestabelecido], para desfrutar de um período de folga em completa liberdade e estabelecer relacionamentos incomuns umas com as outras. É verdade que nenhum elo consistente é formado na maioria das vezes, mas a breve coexistência dessas palavras, expressões e objetos fora de suas condições lógicas usuais expõe uma ambivalência inerente. Seus múltiplos significados e potencialidades, que não se manifestariam em condições normais, são agora revelados (BAKHTIN apud HALL, 2008, p. 210).

O universo cultural onde o trabalho do barqueiro era exercido, ou seja, dentro do barco, é um lugar convencional no qual as relações de dominação entre patrão e empregado se repetem no cotidiano do rio, mas é também de exceções em que a imprescindibilidade desse trabalhador permite a constituição de um diálogo de outro tipo, aquele que permite uma suspensão da fala do patrão/narrador e enuncia, de formas múltiplas, 
as vozes dos barqueiros, vozes que algumas vezes sinalizam o desejo, ainda que inconcluso, de transgressão. Por outras palavras, abordaremos estas representações a partir de um viés que busca compreender os significados dos costumes para além do sentido de cotidiano tratado como consenso social. Reconhecemos que lidar com os costumes e as práticas de trabalho dos barqueiros para além de sua relação com o cotidiano é algo problemático desde o princípio, pois a ausência de um letramento entre esses trabalhadores faz com que sua cultura tenha sido preservada somente por meio das narrativas dos grupos letrados. Por outro lado, mesmo desconfiando dos filtros a que foi submetida tal cultura, pretendemos trabalhar com essa noção, considerando que:

Longe de exibir a permanência sugerida pela palavra 'tradição', o costume era um campo para a mudança e a disputa, uma arena na qual interesses opostos apresentavam reivindicações conflitantes. Essa é a razão pela qual precisamos ter cuidado quanto a generalizações como 'cultura popular'. Esta pode sugerir, numa inflexão antropológica influente no âmbito dos historiadores sociais, uma perspectiva ultraconsensual dessa cultura [...] (THOMPSON, 1998: 16-17).

Abraçar esta visão significa dizer que negamos a ideia de uma cultura que se baseia no consenso, pois o partilhamento cultural tem sua base na negociação e esta nunca é construída em campos que apenas se opõem, mas que também se complementam. Os barqueiros, na forma apresentada pelos narradores que aqui serão analisados surgem como sujeitos frutos desses costumes tão bem retratados pelo médico, mas que, por força da própria narrativa, são "também um conjunto de diferentes recursos, em que há sempre uma troca entre o escrito e o oral, o dominante e o subordinado" (THOMPSON, 1998, p. 17). Assim, fugiremos da tentação de folclorizar os barqueiros e, então, buscaremos uma perspectiva menos confortável, mas que é mais coerente com a labuta e a força desses sujeitos sociais. 
FRANCISCO AYRES DA SILVA: BARCOS, BARQUEIROS E O MÉDICO EM VIAGEM PELOS RIOS

francisco Ayres da Silva é um nome singular na história do Norte de Goiás, atual Estado do Tocantins. Nascido em Porto Imperial atual cidade de Porto Nacional -, em 1872, foi o primeiro filho da terra a formar-se em medicina, no ano de 1899, na cidade do Rio Janeiro. Filho do coronel Joaquim Ayres da Silva, após terminar o curso de medicina, retornou ao rincão portuense para assumir a cadeira de Português e Francês, mas não se contentou apenas com o magistério e a medicina: aventurou-se pela imprensa, fundando, em 1905, o Jornal Norte de Goyaz. Atuando como jornalista, defendia que o governo do Estado de Goiás voltasse seus olhos para a região norte do Estado, o que Ihe conduziu à carreira política em que atuou até sua morte, no ano de 1957.

Assim como o seu pai, coronel Joaquim Ayres, Francisco Ayres se dedicava ainda aos criatórios de gado e ao comércio pelo rio Tocantins, ou seja, era um comerciante que empreendia longas viagens por este rio em direção a Belém e levava diversos produtos da terra, que eram comercializados pelo caminho e, então, retornava do Pará com outras mercadorias, que eram vendidas ao longo do rio ou nos empórios de Carolina, sul do Maranhão, e Porto Nacional, à época, Estado de Goiás. Defensor do desenvolvimento econômico como fonte de progresso do norte goiano, Ayres da Silva escreveu discursos e publicou crônicas nos quais divulgava seu entendimento de que seriam as vias fluviais que resolveriam o problema do norte de Goiás:

A viatura fluvial do Tocantins e Araguaia a qual alude o decreto e nos mereceu as presentes linhas longe de ser um problema nacional, atento às grandes energias latentes que irá despertar, energias que irão cooperar fartamente para os cofres da nação, dos Estados e dos municípios. Custa mesmo a acreditar que, após tantos anos de governo republicano, não fosse cogitado o problema da viação fluvial e a ligação dessas viaturas por meio de estradas de rodagem, uma vez que as circunstâncias do momento não permitam pensar em estradas de 
ferro para regiões de população menos densa (REVISTA INFORMAÇÃO GOYANA, AGO/1925, p. 02).

A citação corresponde a um trecho de um discurso de Francisco Ayres da Silva dirigido ao Governador do Estado quando deputado, que foi veiculado na Revista Informação Goyana. Os argumentos de Ayres da Silva se voltavam para a necessidade de investimento na navegação fluvial como um instrumento de desenvolvimento, não apenas do norte de Goiás, mas também de todo o Brasil. Apesar de o decreto ter sido assinado pelo governador, sua execução teria encontrado dificuldades por parte das autoridades goianas que estavam focadas no desenvolvimento do sudoeste goiano, a partir da chegada da estrada de ferro nessa região. Diante desse 'desinteresse', não é de admirar que a navegação tenha resistido, desde seu início, com a chegada dos bandeirantes paulistas no século XVIII, em função da iniciativa particular dos homens da região, dentre eles o pai de Ayres da Silva, Joaquim Ayres da Silva, que, sendo um fazendeiro com destacável visão comercial, defendia a navegação como solução para o norte goiano e criticava a falta de iniciativa do Estado, como se pode observar no excerto seguinte:

Sempre que vem à baila o já envelhecido problema dos transportes em Goyaz, realça, em primeiro plano, entre medidas solucionadoras a da adaptação dos rios Araguaya e Tocantins à navegação a vapor. É mesmo voz geral, entre os entendidos no assumpto, ser esse o caminho que, mais directamente, o leva a uma finalidade vantajosa. Planos diversos têm sido lembrados sem que, até hoje, nenhum resultado se tenha colhido, mormente para o Estado de Goyaz. Tal insucesso, ao que parece, motiva-se antes da insuficiência das medidas realisadas do que, propriamente de sua impossibilidade de execução (REVISTA INFORMAÇÃO GOYANA, 1924, p.10).

Essas considerações de Joaquim Ayres foram sucedidas pelo discurso de Ayres da Silva, um ano depois, como se pode ver neste outro fragmento:

Mercê desse erro ou dessa curteza de visão [a falta de investimento na navegação do rio Araguaia e Tocantins] é que damos o surpreendente 
disfructe de sermos um paiz eminentemente agrícola e estamos a importar desde a massa formidável do trigo até o feijão, o arroz, o milho, etc., quando de tudo isso se produz fartamente e não póde entrar em giro e perde-se, muita vez, por falta de transporte (REVISTA INFORMAÇÂO GOYANA, AGO/1925, p. 02).

Mesmo a par de todas essas dificuldades, Ayres da Silva e muitos outros comerciantes nortistas jamais deixaram de realizar transações comerciais com Belém do Pará, conduzindo em suas embarcações ao menos em uma ou duas viagens anuais aqueles produtos que, citados no último trecho, o médico diz ficarem 'sem giro'. Nesse sentido, a obra, Caminhos de Outrora: diário de viagens, da qual vamos colher as representações sobre o mundo do trabalho e dos costumes dos barqueiros, é resultado de uma daquelas viagens que, além de fazer circular mercadorias e produtos, movia histórias, pessoas e culturas. Escrito durante uma viagem realizada no ano de 1920, esse diário foi publicado somente em 1972, ou seja, 15 anos após a morte do autor. Este é um dado importante, pois, sendo jornalista e possuindo à sua disposição um jornal no qual poderia imprimir seu diário, é significativo que essa obra só tenha sido publicada após sua morte.

Não temos elementos para promover tal discussão neste artigo, mas é possível que tenha sido uma publicação comemorativa da morte de Ayres da Silva, ou, então, os assuntos discutidos no diário tenham despertado interesse a partir da década de 1970, quando Goiás estava sendo (re) descoberto pelos estudiosos e pela Academia. Esse diário de viagem traz narrativas que informam sobre o cotidiano no 'mundo do barco' bem como as impressões de Ayres da Silva sobre as cidades e povoados pelos quais o barco nomeado Cristal transitava e, principalmente, faz considerações etnográficas sobre os sertanejos do Tocantins; dentre eles, os barqueiros. Segundo diz Joaquim de Oliveira, comentador de Caminhos de Outrora:

A vida, alimentação, os costumes, as crenças, a maneira do sertanejo se expressar, os meios de transporte e comunicações, as lutas políticas, sociais e familiares do povo das regiões palmilhadas, as doenças 
e suas curas domésticas, a morte, observados e descritos há meio século, se retratam e se pintam, com sangue, lágrimas e suores, neste diário de viagens. E também a indiferença dos governantes diante de tais quadros desumanos (O POPULAR - Suplemento Literário, de 23/07/1972, p. 10 - ênfase no original).

Essa abordagem do caráter humano do sertão do Vale do Tocantins, em Ayres da Silva, é uma das características mais marcantes de sua escrita e, talvez por ser médico, detém-se nos detalhes dos acontecimentos e nas minúcias observadas, transformando seu diário de viagem em uma fonte privilegiada sobre o conflito em torno dos costumes dos barqueiros no interior dos barcos. As observações em torno do mundo das viagens fluviais, dos barqueiros e dos barcos se iniciam ainda no embarque em Porto Nacional, quando, em 21 de março de 1920, um domingo, Ayres da Silva - o patrão -, piloto e barqueiros deixam o porto descendo o rio Tocantins a bordo do bote Cristal. A narrativa conta:

O bote Cristal é uma tosca embarcação de alguns metros de comprido, por 4 ou 5 de largo, calando pouco menos de um metro. Compõe-se o bote de duas casas, sendo uma à popa e outra à proa, esta maior que aquela, separadas por um pequeno espaço de pouco mais de metro, forrado com tábua, chamado tombadilho (AYRES DA SILVA, 1972, p. 17).

Essas duas casas serviam para organizar os espaços no barco, inclusive qualificando as mercadorias transportadas:

O compartimento da frente, chamado proa ou paiol é maior quase o dobro, da casa de trás, a popa, é aí que se acumulam ou são conduzidas todas as mercadorias grosseiras, como sal, ferragens, gêneros chamados de estiva, bem assim o todo reduzido serventuário da população, tanto mais crescidas em número, quanto maiores os botes. A outra casa, a popa recebe os gêneros mais nobres, como fazendas, etc., bem assim como os objetos mais nobres da alimentação: café e objetos de uso diário do patrão, piloto, popeiros e passageiros (AYRES DA SILVA, 1972, p.17-8).

O espaço dividido do barco comportava uma separação entre os produtos. A proa estava destinada aos produtos mais grosseiros e, a popa, 
por sua vez, às mercadorias e aos produtos da alimentação mais 'refinados' que seriam consumidos por patrões, pilotos, proeiros e, eventualmente, algum passageiro. Quanto ao uso dos espaços pelas pessoas há, também, uma separação bem demarcada:

O paiol fica de tal forma entulhado que mal cabe os pequenos sacos em que cada tripulante conduz sua rede, sua roupa, o fumo, os cigarros. [...] O paiol que chega até o forro de proa recebe, numa promiscuidade desconcertante [...] estando um pequeno espaço de alguns centímetros, onde os tripulantes se assentam. [...] Atrás, à popa existem os popeiros. São homens de confiança e se encontram mais em contato com o patrão e com o piloto [...] (AYRES DA SILVA, 1972, p. 18-9).

A organização dos espaços do barco era indispensável tanto à funcionalidade da carga quanto para um melhor aproveitamento da força de trabalho na condução da embarcação, visto que o bote Cristal era o maior e mais importante que realizava o transporte de mercadorias na região norte de Goiás. Entretanto, lado a lado com os requisitos da funcionalidade existia um exercício de hierarquização social em decorrência da divisão do trabalho. O espaço destinado aos objetos dos remeiros era reduzido, entulhado e exíguo, restando-Ihes viver promiscuamente, "especialmente devido à falta de cuidado pessoal" (AYRES DA SILVA, 1972, p.21). Dentro dessa hierarquização, os pilotos e os popeiros eram os homens de confiança do patrão, que dividia com eles mais do que as maiores responsabilidades, chegando a dividir os espaços mais amplos, nos quais a dignidade e o status quo eram, assim, preservados.

Por outro lado, a ideia da promiscuidade 'desconcertante e incômoda', afirmada e reiterada por Ayres da Silva quando se refere aos tripulantes [remeiros] não tem sua causa apenas nos espaços exíguos que ocupavam, mas também nas representações simbólicas que marcam esses trabalhadores. Um imaginário que vinculava a imagem do barqueiro à decadência social e moral foi construído desde as primeiras rotas de viagens 
pelo Tocantins, ainda no século XVIII, e permanece, mesmo nos dias atuais, nas redes de significados produzidos, por exemplo, na literatura. No romance Perpetinha: um drama nos babaçuais, de Carmo Bernardes ${ }^{7}$, publicado em 1991, há um exemplo de sobrevivência da imagem da promiscuidade e da decadência dos barqueiros. Em Bernardes, a construção do sentido se inicia com o nome apropriado por ele da memória histórica e da tradição regional para indicar os remeiros: porcos d'água. Narrando a viagem de barco da personagem Armantino pelo rio Tocantins até Boa Vista, atual Tocantinópolis, esse literato apresenta haver um ordenamento social na embarcação:

Patrão e piloto são casteados, não dão confiança a 'porco d'água' [remeiros]. Era para as duas categorias não terem mesmo condições de diálogo. Nunca iam entender os sentimentos íntimos uma da outra. O piloto é irmão de classe dos outros trabalhadores do rio. Proletário com mania de grandeza. Representa com fidelidade o orgulho balofo da profissão. A história criou para os pilotos de barco da navegação fluvial uns tantos privilégios miúdos, tornou-os tiranetes. Ele é quem dispõe sobre as paradas. A hora e os locais dos pousos ele é quem marca. A precedência de fazer seu prato, nas refeições, é sua. Como se comida dos embarcadiços fosse de muita iguaria (BERNARDES, 1991, p. 29-30).

Não é o caso de concebermos que as relações entre barqueiros e patrões eram baseadas em divisões de classe, embora a luta de classes estivesse dada muito antes do próprio surgimento da classe e dos termos políticos em que foram postos modernamente as 'classes sociais'. No entanto, a narrativa ficcional não se preocupa com a anacronia da linguagem, muito pelo contrário, a intenção literária, ao que parece, principalmente no caso de Bernardes (1991), é (re)construir esse imbricamento: um jogo entre uma linguagem bem situada dentro das explicações da dominação do trabalho e outra mais representativa das situações costumeiras no sertão. O matiz dado a essa questão exige entendê-la não como divisão, mas como uma hierarquização que se revela através da retina do narrador-onisciente como um elemento da formação cultural da região. Observamos esse aspecto 
quando o narrador coloca as diferenças entre Armantino, a personagem principal, e o dono/patrão do barco:

No decorrer da viagem passou a haver uma incompatibilidade difícil de conciliar-se. E isto a sociologia explica. Ódio de classe. O rapaz, uma criatura sensível, integrado emocionalmente na natureza, poeta, romântico, alma cismadora. O outro, um elemento duro, desses viventes que só concebem a vida no sentido prático. Uma personalidade marcada pela ganância a que a exploração do semelhante é muito natural. Justo, portanto, não terem diálogo (BERNARDES, 1991, p.32).

A ideia de separação apresentada no romance não é aquela situada na divisão de classe, mas a que permeia as diferenças culturais mediadas por elementos cognitivos, as formas pelas quais os homens compreendem o mundo. Armantino era sensível e poeta, ao passo que o dono do barco era prático e ganancioso. Patrões e pilotos eram casteados, ou seja, pertenciam a uma hierarquia sociocultural distinta, à medida que os remeiros eram os porcos d'água, os párias sociais. Dessa voz saída da literatura não nos interessa os elementos reproduzidos do real, mas a construção semântica da qual nos apropriamos para buscar compreender como Ayres da Silva representa a divisão da 'casca de noz', que era o barco, não apenas a partir de sua condição social e econômica, mas sim de seu horizonte cognitivo, sua forma de compreender os homens. Portanto, temos que considerar a narrativa de Ayres da Silva para além da memória, que dizer, tratá-la como uma representação 'do olho que vê o mundo', pois "entre o que seus olhos viram e o que compreendeu, medeia uma distância, coberta por sua visão" (MOREYRA, 1988, p. 165).

Seguindo Sérgio Paulo Moreyra (1988), observamos que entender os significados do relato de Ayres da Silva passa pela observação de que seu texto não tem uma relação apenas com a memória, principalmente porque o diário foi escrito no decorrer da viagem, mas também com as representações: representações do mundo da navegação, do sertão, dos 
barcos e dos barqueiros. Essas representações não estão necessariamente ligadas às intenções do autor, a considerar que:

Na transição da fala para a escrita, da oralidade para o texto, é necessário efetuar a dissociação entre aquilo que está escrito e a intenção mental do seu criador no momento em que escreveu, pois o que o texto significa é mais importante do que aquilo que o autor quis dizer quando escreveu a obra (BRANDIM, 2010, p.142).

Esse significado do texto, de que fala Ana Cristina Meneses de Sousa Brandim, é algo que se forma do encontro entre as intenções representadas, a realidade vivida e a memória narrada, apontando na direção do discurso como algo que está entre a linguagem e a experiência (BRANDIM, 2010). Assim, no relato de Ayres da Silva o sentido do discurso, que vai além do que explicitamente é narrado, se produz em um diálogo intrinsecamente tenso, que deixa entrever também a voz representada dos remeiros em uma luta que tem sua base no costume e nas práticas de trabalhar. O lugar dos homens no barco pode ser definido em função do ofício que realizam, mas as representações dessa organização feita por Ayres da Silva evidenciam uma hierarquização sociocultural relacionada à visão de mundo do autor, mas também aos diversos diálogos constituídos acerca da navegação em Goiás e das relações simbólicas entre pobres e ricos.

Sobre a questão da navegação, a própria viagem realizada por Ayres da Silva, que era o dono do barco, mas não costumava acompanhar suas viagens para Belém, está relacionada às discussões em torno da navegabilidade do rio Tocantins que encontrava forte rejeição na administração goiana. Segundo o médico:

A primeira tentativa de navegação data de 1774 . De então em diante, não mais cessou o rio de ser trafegado anualmente pelos toscos botes, mesmo no sertão arranjados. Pois bem, até agora, como auxílio direto a favor de melhoramento para o rio, a tentativa de Lago, engenheiro que ao tempo do regime monárquico foi incumbido de estudar o rio e melhorar-Ihe a navegação, foi a única existente. O Dr. Lago não fez, propriamente, serviço algum no rio, apenas limitou-se a abrir estradas 
marginais, nos pontos encachoeirados. Na República, o Congresso concedeu cinquenta contos para os serviços das cachoeiras a que acima nos reportamos. O governo do Estado, de posse desse dinheiro, aplicou-o em viagens exploradoras do [rio] Maranhão e, diz-se, em concertos no Palácio de Goiás! De modo que dinheiro eficientemente empregado em benefício do rio não se registra soma útil (AYRES DA SILVA, 1972, p. 21).

As relações simbólicas travadas no rio durante a viagem e representadas por Ayres da Silva são em pequena escala a compreensão desse médico sobre as relações entre abastados e pobres no sertão do norte de Goiás, concentrando-se essa relação nas disputas cotidianas, espaço no qual os sertanejos pobres, assim como os remeiros, conseguem se mover com mais desenvoltura, mesmo e a despeito das hierarquias sociais e espaciais dentro e fora do barco.

\section{DENTRO DO BOTE: AS DISPUTAS EM TORNO DA ALIMENTAÇÃO}

Logo após o embarque, as relações dentro do barco se tornam mais estreitas, não tanto pelos espaços restritos, mas porque os homens todos os homens que habitam aquele espaço-passam a se olhar mais de perto. Esse 'olhar de perto' produz efeitos implícitos em Ayres da Silva, efeitos que são transpostos para sua narrativa e, nesse sentido, uma dimensão que retorna constantemente em seu texto é a questão da alimentação. Logo no início da viagem, ele aponta sucintamente esse ponto ao afirmar que "a alimentação de todo pessoal se faz à custa do patrão, dono do bote. É composta quase exclusivamente de carne, farinha de mandioca, algum arroz e feijão" (AYRES DA SILVA, 1972, p. 20). A composição da alimentação, apresentada acima de forma genérica, vai aparecendo em suas particularidades e hierarquização no decorrer do relato, à medida que o médico descreve os momentos das refeições. Assim, para o dia 22 de março de 1920, descreve: 
Ao meio dia aportava-se no porto do Canela para o almoço. Tinhase percorrido cerca de cinco léguas. Em que consiste o almoço dos barqueiros? O contraproeiro vai ao depósito de carne, a que nos aludimos atrás, tira um dos pacotes chamados grajaus uma boa porção, leva-a para o forro de proa e ali, à voz do 'vamos ao boi, rapaziada', cada qual se aproxima, tira uma boa maquia, e isto é, com uma boa porção de farinha, que constitui o almoço do pessoal remeiro. Cada qual lava sumariamente seu naco, espeta-lhe um pedaço de pau, previamente talhado e aguçado, e leva-o ao lume. E quando estão bem assados passa a saboreá-lo com a farinha de mandioca, ligeiramente umedecida com água do rio (AYRES DA SILVA, 1972, p. 22).

Nesse trecho encontramos algumas diferenças em relação ao relato anterior, pois ao menos nesse dia a alimentação dos remeiros se constituiu apenas de farinha e carne, não tendo arroz ou feijão. Por outro lado, a refeição do patrão, "consisti de feijão, arroz, carne, ovos, doces e café. Da refeição do patrão participa o piloto e as sobras fazem as delícias dos popeiros" (AYRES DA SILVA, 1972, p. 22). Sobre os demais barqueiros ainda diz: "terminada a refeição frugalíssima, cada qual guarda qualquer cousa do naco preparado, e mais tarde, entre o almoço e a ceia, de quando em quando, mastigam qualquer cousa, sempre carne e farinha" (AYRES DA SILVA, 1972, p. 22). A alimentação dos barqueiros seria formada basicamente de farinha e de carne, enquanto que a do patrão que era partilhada pelo piloto e pelos popeiros, considerados os homens de confiança por Ayres da Silva, continha arroz, feijão, farinha, carne, ovos e café. Observemos, ainda, a variedade da alimentação do patrão a partir da ótica da divisão e da hierarquização no bote. Nos dizeres de Ayres da Silva (1972, p. 32):

O outro serviço é o da cozinha do patrão. Para este há sempre um cozinheiro especial, cujo mister é preparar o alimento do patrão, do piloto de botes, bem assim para os popeiros que auxiliam nas confecções culinárias. A cozinha se assenta em um pequeno espaço do tombadilho, e graças a um caixão com areia molhada, ao qual se sobrepõe um pequeno fogareiro com duas ou três panelas. Está o cozinheiro preparado para suas confecções, que não passam além do feijão, arroz, carne e ovos. O feijão, ordinariamente, é feito com carne 
e toucinho; o arroz, ora simples, ora com carne e o cirigado. Se há abóbora, girimum ou moranga, tem se a mistura para a carne.

Essas diferenças eram e são comuns entre trabalhadores pobres e aqueles com alguma especialização. Todavia, no trecho acima vemos uma ambivalência se manifestar na narrativa de Ayres da Silva em dois sentidos: de um lado, ele deixa entrever novamente que a alimentação dos patrões é mais variada que a dos barqueiros, embora na sua concepção não 'passe dos mesmos itens ordinários', e, de outro, mesmo após a descrição de sua alimentação como 'arroz, carne, feijão e ovos como básico ordinário', registra dois novos produtos: toucinho, um alimento altamente calórico, e abóbora. Assim, se somarmos todos os itens citados da alimentação do patrão e os compararmos com aqueles que compõem a alimentação ordinária da tripulação, teríamos: arroz, feijão, farinha, carne, ovos, café e abóbora para o patrão e farinha e carne para a tripulação.

Compreendemos que a questão alimentar causa incômodo em Ayres da Silva, pois, não poucas vezes, tenta evidenciar haver uma igualdade entre o que come a tripulação e o que comem patrões, pilotos e popeiros. No entanto, não cremos que esse incômodo se deva ao fato de se preocupar com a hierarquização entre patrões e tripulantes, mas ao fato de reconhecêla como um ponto de tensão dentro do barco, algo que os remeiros disputam com afinco. A alimentação do barqueiro, constituída ordinariamente de farinha, carne e jacuba, 'uma mistura de farinha, rapadura ou açúcar e água', não tinha nutrientes suficientes para garantir a energia necessária ao trabalho de doze (12) horas no remo das embarcações. Desta maneira, uma maior quantidade de carboidrato e de gordura, representados pelo arroz e pelo toucinho, melhoraria suas vidas e isso era algo que os barqueiros entendiam. Tal constatação pode ser observada quando a tripulação se vê privada da rapadura, com a qual faziam a jacuba, que, por se constituir de carboidrato 
simples, fornecia uma carga de energia imediata. Nessa ocasião, Ayres da Silva (1972, p. 35) assim se manifesta:

Nos [cachoeira dos] Mares [depois de dois dias sem rapadura] foi distribuída uma ração de rapadura [...]. Os remeiros se vingam fartamente dessa falta dos patrões, ingerindo a todo instante biscoitos (mocororos) bem adocicados de que trazem os sacos bem amarrados. Nesse passo nada fazem mais do que ir ao encontro de uma exigência natural que propele o indivíduo a apetecer tanto mais hidrocarbonatos quanto mais dispende energias musculares.

Queremos discorrer sobre alguns pontos deste trecho. Em primeiro lugar, o termo vingança é bem adequado para caracterizar as intenções dos barqueiros, dado que esses de fato pretendiam, ao menos em parte, se vingar dos patrões e, em segundo lugar, embora o médico não explique a vingança de que ele fala, parece tratar-se do fato de que os sacos de biscoito consumidos pelos barqueiros pertenciam apenas ao patrão e ao piloto, quer dizer, algo de consumo exclusivo da 'elite' do barco; consumo casteado, como diria Carmo Bernardes. Em terceiro lugar, a vingança se dava não somente por causa do atraso de um dia, mas também em função da interrupção do fornecimento ter sido de um produto importante na aquisição de energia desses trabalhadores e, principalmente, por ser uma quebra do costume, considerando que a distribuição da rapadura era uma obrigação do patrão.

As tensões entre patrão e tripulação na viagem comandada por Ayres da Silva era algo crescente, como bem assim revela o próprio médico em 1 으 de abril de 1920. O fato de a rapadura estar sendo distribuída apenas ocasionalmente fez com que "alguns tripulantes te[nham] comprado rapaduras, há alguns dias, e então repartem-nas por entre os amigos, e assim vão melhorando sua matéria alimentar" (AYRES DA SILVA, 1972, p. 43). O motivo da tensão, da qual decorre a vingança, se evidencia: a alimentação dos tripulantes que Ayres da Silva diz ser de responsabilidade do patrão no início de seu diário, como apontado anteriormente, estava sendo assumida 
também pelos barqueiros. Diante da dificuldade de seu trabalho e das poucas expectativas que tinham em relação ao seu ofício, a instância alimentar se tornava um âmbito que parecia mobilizar a subjetividade e distinguir os brios desse trabalhador dentro do mundo sertanejo. Assim, a quebra das regras estabelecidas pelo costume de fornecimento alimentar gerou uma crise no mesmo dia em que os barqueiros comeram os biscoitos do patrão. Em 27 de abril de 1920, ocorreu o seguinte episódio:

À noite teve um símile de greve entre tripulantes: recusaram a ceia porque, como disseram, o toucinho dado para sua confecção era de barrão [porco não castrado]; tinha almíscar de barrão! Vê-se bem que o motivo é fútil e apenas deixa transparecer que por aqui também há espíritos de revolta (AYRES DA SILVA, 1972, p. 35 - ênfase no original).

Dois aspectos importantes salta aos olhos da leitura do trecho.

Primeiro, depois da tripulação se mostrar insatisfeita por causa da suspensão da rapadura e comer por vingança os biscoitos do patrão é possível que Ayres da Silva tenha oferecido feijão com toucinho como uma tentativa de negociar uma trégua, que, ao que parece, não surtiu efeito. Segundo, não há como saber se o toucinho tinha ou não cheiro e sabor desagradável, mas também há a possibilidade de que fosse uma estratégia dos barqueiros para demonstrar aos chefes do bote Cristal que algumas coisas não eram negociáveis. Dito de outro modo, os barqueiros usaram o costume para demonstrar que, embora aceitassem a exploração de sua força de trabalho, havia limites para a dominação e que, no caso do patrão não entender, a greve era uma alternativa que eles estavam dispostos a usar. De fato, desde o século XIX, recorrer à paralisação ou à ameaça de paralisação do trabalho era uma estratégia empreendida pelos remeiros para atingir diferentes objetivos. Tal estratégia ia desde a realização de suas festas nos povoados quando os barcos paravam a até descansar das longas viagens, como conta o presidente da província de Goiás, Joaquim Almeida de Moraes Leite ${ }^{8}$, em 1882, sobre um atraso no embarque de sua tripulação: 
Mas como os tripulantes, uma vez nestes presídios, fazem a sua greve e só embarcam após muitos dias, julguei que houvesse alguma combinação entre eles para que aquela demora no obrigasse a fazer pouso no São José dos Martírios (MORAES LEITE, 1999, p. 223 - ênfase no original).

Contudo, alimentação ainda era um dos principais motivos de tensão no interior dos botes e uma das mais fortes motivações de paralização do trabalho pelos barqueiros. Um aspecto que fazia toda a diferença era o tipo de carne que era oferecida ao barqueiro. No caso da viagem de Ayres da Silva, inicialmente, aparenta se tratar exclusivamente de carne bovina, pois a expressão para chamar as refeições indica isso: 'vamos ao boi, rapaziada!'. No entanto, o próprio Ayres da Silva esclarece que não era bem assim ao descrever a função de uma pequena embarcação que acompanhava o bote Cristal. Ele diz:

As montarias são as canoas onde viaja o patrão em cobrança, venda ou mesmo em arranjo de alimentação para a tripulação. Em tal caso a montaria se diz mariscadeira e a ela incumbe a caça, a pesca, durante a noite, para o suprimento do bote (AYRES DA SILVA, 1972, p. 20).

É-nos esclarecido neste recorte que a carne consumida pela tripulação - que certamente não incluía o patrão, o piloto e os popeiros - era constituída muitas vezes de peixes e de carne de animais silvestres. A pescaria e a caça eram tão importantes para o sucesso da viagem que, 63 anos antes da viagem de Ayres da Silva, em 1847, Rufino Theotonio Segurado ${ }^{9}$ explicou o seguinte:

Chegamos à ilha que denominei Três Fugidos, porque nesse lugar se evadiram três camaradas [remeiros], levando consigo a montaria de caçar, três remos [...] vindo desse lugar para cima a haver a falta de nove pessoas, que deviam compor a tripulação, notando-se entre estas a do caçador, que substituía um dos pilotos, o qual tinha falecido; acontecendo que achei-me com falta de dois objectos tão essenciais na navegação actual, a saber, o caçador e a montaria de caçar (SEGURADO, 2008, p. 46). 
De acordo com Segurado, a viagem dependia da pescaria e da caça regulares que, acompanhadas da farinha de mandioca, compunham a alimentação da tripulação. Além disso, no caso de escassez desses víveres o que restava ao barqueiro era a rebeldia:

Continuando a dá-la em rações ordinárias ou de tê-la em pequenas rações por mais tempo, preferi o segundo expediente. Isso, porém, dava causa a repetidas e rancorosas murmurações, das quais pareceume quererem passar a vias de facto. Suspeitando, pois, alguma trama, chamei a um camarada [barqueiro] que me parecia cabeça, e entendendo-me com elle procurei fazê-lo entrar na razão, e com effeito pareceu-me havê-lo conseguido (SEGURADO, 2008, p. 447).

Deserções, murmurações, tramas, vinganças e greves não eram sinais abertos de revolta, mas de uma negociação cultural permanente. De qualquer forma, o que incomodava a todos os patrões que comumente são os narradores privilegiados da história dos barqueiros é o fato desses homens construírem, ainda que à força, espaços de luta a partir dos quais buscavam permanentemente alargar suas condições de resistência cultural. Ayres da Silva conhece os mecanismos usados por sua tripulação, sentindo-se, ao mesmo tempo, impotente diante dessas estratégias e, por isso, sua constante referência à alimentação no relato. Por outro lado, em sua necessidade de controle, não é capaz de falar abertamente sobre o conflito em torno dos costumes alimentares, pois, sendo jornalista, sabia das implicações do que escrevia. Vejamos o que escreveu ao final da viagem que coincide com o final do relato de viagem:

A tripulação é ordeira, amante do trabalho e, ao menor aviso ou sinal, estão todos a postos no desempenho de seus serviços, zelando pelo interesse do patrão, desde o piloto até o mais modesto barqueiro. De uma feita houve um início de greve, apenas prejudicial ao estômago dos tripulantes e que, felizmente, se não reproduziu mais. Não tem regime alimentar: amanhecem comendo e anoitecem comendo [...] tanto mastigam a carne assada, a farinha, isto de dia e de noite. Ainda no Tocantins, quando há biscoitos (mocororos) servem-se deles a todo instante! É possível que tal regime, longe de ser útil, prejudique-os e os 
torne em condições de inferioridade, se acaso são atacados de algum mal. Tivemos ocasião de observar que os dois primeiros gripados do bote foram exatamente os mais gastrônomos. Há de se notar ainda que ficou pior o que mais comia dentre os dois (AYRES DA SILVA, 1972, p. 86).

O trecho acima é dissertado por Ayres da Silva no final do diário de viagem e é sua última referência aos barqueiros. De um lado, ele corrige sua narrativa anterior ao reconhecer o valor dos trabalhadores barqueiros e, de outro, volta a se referir ao princípio de greve como um acontecimento isolado e de pouca importância, que só prejudicou 'as barrigas' dos tripulantes que se recusaram a comer. Sua abordagem desse acontecimento como um 'incidente' parece-nos representar bem seu desejo de mostrar um norte de Goiás ordenado, com trabalhadores disciplinados e prontos para o desenvolvimento da navegação, desenvolvimento pelo qual há muito lutava. Nesse momento, o político falou mais alto que o patrão. Contudo, mesmo suplantado, em sua retórica pelo político, o patrão não é silenciado, o que em diversos momentos faz surgir também à resistência do barqueiro.

O problema da alimentação da tripulação, um ponto delicado na empresa da navegação desde o século XIX, retornou disfarçado pelo discurso médico de Ayres da Silva quando ele aponta que a alimentação excessiva é a causa principal dos males que atingem a tripulação, principalmente o consumo que fazem dos biscoitos doces pertencentes ao patrão. Porém, não parece ser os problemas de saúde da tripulação que preocupam o médico, mas sim o não deixar transparecer na sua escrita qualquer relação entre as tensões vividas durante as viagens e os meios que trabalhadores/barqueiros elaboravam para prejudicar os patrões, o que, muitas vezes, consegue com eficácia.

No entanto, a despeito dos significados pretendidos por Ayres da Silva, outros sentidos são produzidos em sua narrativa, sentidos que, na interface de um diálogo com outras narrativas, nos permite evidenciar a 
agência dos barqueiros na luta para resistir à dominação e à disciplinarização para o trabalho que o projeto de desenvolvimento sonhado pelo médicocomerciante exigia. Nesse sentido, essa resistência se dava mediada por rituais que ultrapassavam a dimensão do trabalho, avançando rumos às dimensões simbólicas disputadas entre trabalhadores e patrões.

\section{CONTROLE E RESISTÊNCIA NOS RITUAIS DE EMBARQUE}

Desde o embarque havia um jogo de forças entre patrão e piloto, de um lado, e remeiros, de outro. Na partida do bote Cristal - uma embarcação que comportava 22 toneladas e que estava carregada de couros, peles silvestres, farinha e fumo - esse jogo é anunciado no relato de Ayres da Silva (1972, p. 22):

É oportuno aqui lembrar uma cousa muito comum no barqueiro: é o vício do alcoolismo. Todos ou quase todos bebem, especialmente ao sair do povoado. Rara é a ocasião em que o bote parte de Porto Nacional sem conduzir crescido número de barqueiros completamente embriagados, por sua vez necessitando da intervenção da polícia para o embarque. O bote Cristal conta uma vitória, pois desta vez apenas um barqueiro saiu em completa embriaguês. Alguns saíram alegres, em todo caso, todos desempenhando galhardamente seu ofício. (ênfase no original).

O consumo de álcool é, certamente, um costume do barqueiro que cruzava os rios Tocantins e Araguaia, mas a prática de atrasar o barco deve ser ampliada para incluir outros significados. Com certeza muitos barqueiros atrasavam a viagem porque ficavam bêbados dois ou três dias antes da data marcada para a partida, sendo necessário algum tipo de escolta no dia da saída. Em um relato de viagem, Josias de Almeida ${ }^{10}$, em viagem realizada em 1912, pelo rio Araguaia, narra aspectos da atividade dos barqueiros e remeiros no contexto do transporte do látex extraído na região 
dos vales e comercializada em Belém do Pará no ápice da 'febre da borracha' nos seguintes termos:

[...]. A mim, cumpria-me descer as trezentas e oitenta léguas de Conceição a Belém e já não seria com os bondosos barqueiros de Santa Leopoldina, homens humildes, obedientes e respeitadores dos patrões, mas, sim, com fera humanas destituídas de qualquer sentimento, capazes de praticar os maiores crimes, sobretudo depois das libações nos portos de escala. Lembro-me de como, na barreira de Sant'Ana, depois de três dias de Embriaguez renovada, as tripulações de Gonçalo Costa recusavam regressar a bordo para o prosseguimento da viagem. Já sem força moral, os pilotos tiveram de ser violentos. Com o auxílio do destacamento local, amarraram os recalcitrantes e metteram-n'os assim nos barcos, deixando-os amarrados até passar o effeito do álcool. Mesmo ahi, todavia, renhida luta se travou, com uso de rifles e carabinas, perdendo a vida quinze barqueiros (ALMEIDA, 1935, p. 47).

Percebe-se aqui a figura do piloto 'sem força moral' para debelar a insubordinação da tripulação. Tal ausência do controle moral de seus subordinados, muito provavelmente, se devesse ao fato dos pilotos, nesse caso específico, terem ficado ao lado do proprietário do barco e não de sua tripulação, algo bastante comum nas situações de tensão e disputas ocorridas entre a tripulação e os regatões ${ }^{11}$. Da atitude dos pilotos em usarem a força, com o auxílio do destacamento local, pode se inferir esse posicionamento. Almeida, uma página adiante, nos dá outra pista: "há patrões que abusam um tanto do princípio de autoridade, e seus actos ríspidos, suas injustiças, suas violências vão dando origem a ódios surdos, a profundas intenções de vindicta" (ALMEIDA, 1935, p. 49). Ao narrar a preparação de uma partida que enfrentaria logo depois de superar perigosas corredeiras, ele nos apresenta um costume presente na árdua profissão daquelas tripulações: "O piloto começa a distribuir cachaça com pólvora aos companheiros, a fim de estimulal-os, fazel-os meio loucos, suffcientemente inconscientes para não perceberem o perigo e não perderem a coragem" (ALMEIDA, 1935, p. 57). Infere-se dessas narrativas que, quando interessava ao regatão e seus pilotos, a aguardente 
era servida até mesmo com pólvora ${ }^{12}$, o que certamente potencializa em muito seus efeitos, mas quando a embriaguês contrariava seus interesses a punição contra a insubordinação poderia culminar até mesmo na morte dos tripulantes, como vimos acima.

Por outro lado, não eram apenas pilotos e donos de barcos que utilizavam as práticas culturais e os costumes dos barqueiros de forma ambivalente, pois muitos barqueiros consumiam aguardente não apenas em situações de riscos, caso das travessias das cachoeiras, pra lhes dar coragem, mas como instrumento de 'vindicta', como esclarece Almeida, contra seus patrões, surgindo aqui outra vez a vingança como uma forma costumeira, surgida na tradição e mantida como forma de resistência, pelos barqueiros. Nesse caso, uma mesma prática, no caso o consumo deliberado de bebidas alcoólicas, assume significados plurais em uma arena social na qual linguagens e rituais plurivalentes eram disputados e causavam tensões a cada nova partida dos botes.

Entretanto, não era somente por causa da ingestão de bebida alcoólica que as viagens atrasavam. Frei José Maria Audrin ${ }^{13}$, contemporâneo de Ayres da Silva em Porto Nacional, expõe essa questão trazendo mais alguns detalhes:

É costume adotado por todos os viajantes prudentes, quanto mais pelos missionários, saírem à tardinha do porto, para passarem a primeira noite a uma certa distância do povoado, por pequeno que seja o percurso efetuado antes de escurecer. Se não tomarem esta precaução verão os pobres barqueiros já meio embriagados durante o dia, continuar suas libações mais copiosas ainda de noite, e amanhecer infalivelmente inutilizados. O melhor, portanto, é obrigá-los a embarcar mesmo fortemente alcoolizados e afastar-se logo, embora já bem tarde (AUDRIN, 1947, p. 228).

Nesse trecho, frei Audrin mostra como os viajantes criaram um costume para combater o hábito dos barqueiros de embebedarem-se no dia da partida dos botes, não se afastando o frade da narrativa de Ayres da 
Silva até esse ponto. Porém, a despeito de reconhecer o alcoolismo, Audrin apresenta elementos voltados para as relações culturais:

Quando outrora os botes desciam de Porto Nacional a Belém, o dia do embarque era de extraordinária emoção. Esses imensos batelões saiam sobrecarregados, tripulados por vinte e quatro remeiros. A viagem além de perigosíssima através de um sem número de cachoeiras, era terrivelmente demorada, pois que, iniciada em Fevereiro, vinha terminar no fim de Agosto. A despedida dos barqueiros era comovente, e para dominar a saudade, afogavam-na em repetidos copos de águaardente. Na hora da partida, estavam todos espalhados pelas ruas e bodegas, quase incapazes de qualquer movimento e decisão (AUDRIN, 1947, p. 228)

A situação etílica dos remeiros é registrada por quase todos os narradores sertanejos que se ocuparam da navegação, porém Audrin, diferentemente de Ayres da Silva, expõe como motivação para a bebedeira os sentimentos dos tripulantes que, sabendo da dificuldade para transpor as corredeiras e cachoeiras do rio Tocantins, compreendiam os riscos que corriam, como, por exemplo, o de nunca mais ver seus familiares: filhos, esposas, pais, mães, irmãos e irmãs. A compreensão de Ayres da Silva para os atrasos nas partidas dos botes encerrava no alcoolismo como única causa. Para esse médico, a afetividade, constituinte da dimensão cultural do sertão, não faz parte da explicação do próprio alcoolismo do qual os barqueiros eram vítimas. É claro que enquanto médico Ayres da Silva procurava encontrar explicações vinculadas às moléstias e doenças que atingem a população do norte de Goiás, porém esta não é a única explicação para excluir de seu relato os aspectos da sensibilidade dos remeiros, como tentaremos demonstrar a seguir.

Estabelecendo algumas comparações, vemos que Audrin traz elementos intersubjetivos para a explicação do atraso nas saídas das embarcações, lançando um olhar para dentro da cultura e resgatar sentimentos como saudade e medo diante das perigosas cachoeiras. Porém, esse frade vai mais além ao postular que:

Euclides Antunes Medeiros | Olívia Macedo Miranda Cormineiro BARQUEIROS, NAVEGAÇÃO E CULTURA 
O estratagema empregado de tempos imemoriais para reuni-los em poucos instantes era o seguinte: A bandeira vermelha do Divino Espírito Santo percorria, ao som dos tambores, todos os recantos da cidade. Vendo-a, os barqueiros que não queriam privar-se da proteção do Santo, no decurso da perigosa jornada, precipitavam-se atrás da imagem sagrada, ou se faziam carregar junto dela. O cortejo barulhento e às vezes lamentável chegava à margem do rio, a bandeira entrava logo no barco e era apresentada aos tripulantes, que a beijavam com frenética devoção. E enquanto estavam ocupados nessa reverência, o patrão dava o sinal, os 'proeiros' soltavam a embarcação e com as suas 'zingas' ou varejões empurravam-na para o largo. Destarte os pobres barqueiros ficavam impossibilitados de prolongar suas despedidas e retardar o início da viagem. A simples presença da imagem do Divino valia, portanto, mais do que as ordens do patrão, mais do que os esforços e ameaças da polícia (AUDRIN, 1947, p. 228-9).

Em Audrin, a questão do atraso e do alcoolismo é relacionada às dificuldades do trabalho no interior de um barco, marcado pelos perigos das cachoeiras, dos ataques dos grupos indígenas e dos problemas de saúde devido à insalubridade e à malária. Dificuldades que eram reforçadas pela duração da viagem, em média 06 (seis) meses, o que significava um longo tempo distante das famílias. Além disso, Audrin (1947, p. 228) aponta que “as observações precedentes [os atrasos, a saída com a bandeira do Divino] provocam [...] uma reminiscência pitoresca que pode servir para fazer compreender o instinto religioso do sertanejo" a que reportamos. Se, por um lado, o frade apresenta a relação entre sertanejos e Igreja, indicando um elo que aponta para a tradição da religiosidade popular, por outro, parece sugerir traços de uma religiosidade popular.

Ao contrário de Audrin, Ayres da Silva leva a questão do atraso mais a 'sério', concebendo-a como um problema de polícia, relacionando-a não à dimensão afetiva e religiosa do sertanejo-barqueiro, mas à da insubordinação dos trabalhadores pobres e, por isso, inclina-se a tratar a dificuldade do atraso como uma questão disciplinar. Apesar de não excluirmos as instâncias 'revividas' por Audrin, concordamos com Ayres da Silva quando aponta na 
direção da insubordinação como um aspecto chave para entender o atraso, porém procuramos fazer uma leitura da insubordinação como resistência de agentes sociais que pareciam compreender o ritual do embarque como parte do jogo e das relações de forças que estavam postas em uma arena comum que evoca significados diferentes daqueles dados na narrativa pelo médico. Além disso, nossa compreensão de resistência é aquela ritualizada n vivência diária desses trabalhadores, tal como posta na citação a seguir:

Por resistência sinalizam-se as formas de desfiliação [...] que de certa forma, representavam as ameaças e as negociações com a ordem dominante, que não poderiam ser assimiladas pelas formas tradições de luta. Já o termo rituais apontava para as dimensão simbólica desses movimentos - estilização das ações sociais, o jogo de signos e símbolos, a encenação da resistência e da repetição do teatro da vida cotidiana [...] (HALL, 2008, p. 214).

Não era possível que houvesse viagem sem o trabalho árduo dos barqueiros, em média um total de dezoito (18), que fendiam com seus remos as embarcações durante os longos seis meses que subiam o rio Tocantins, e os patrões, a polícia e os padres sabiam bem disso. O problema que queremos levantar, porém, é que os remeiros/barqueiros também consciência desse fato e usavam os atrasos para estabelecer desde antes do embarque alguns pontos de negociação. $\mathrm{O}$ objetivo dos barqueiros não era impedir a viagem, muito menos não embarcar, mas sim registrar que tinham algum poder de barganha, e um exemplo disso é o fato de que muitos deles quando eram deixados para trás, pois muito bêbados não apareciam para o embarque, "pegavam uma canoa e corriam atrás do bote, depois de curado o efeito da cachaça, mesmo insatisfeitos com o patrão e o piloto porque deixara-os no porto" (AYRES DA SILVA, 1972, p. 48).

Igualmente, mesmo a polícia não tinha a pretensão de prender ou de ferir gravemente os barqueiros, pois o objetivo era fazê-los embarcar. Nesse caso, muitas vezes a ação da polícia não era a mais eficiente para fazer o barqueiro embarcar, a não ser que estivessem dispostos a carregar todos os 
tripulantes para o interior do bote, algo que seria muito difícil de conseguir apenas 'debaixo de ameaças', afinal de contas, a tripulação conhecia sua imprescindibilidade no bote e, com isso, negociava mais um dia no porto, ao lado de seus familiares, amigos e amores. Talvez por isso Audrin (1947, p.228) diga que o "costume adotado pelos viajantes [...], estratagema de tempos imemoriais para reuni-los [...]", seja o uso da bandeira do Divino Espírito Santo, uma vez que, para o barqueiro, isso seria uma forma de demonstrar que não fora pela força que entrara no barco, mas em função de seus costumes e de suas crenças.

Joaquim de Almeida Leite Moraes, no seu relato Apontamentos de Viagem ${ }^{14}$, tendo aportado no Presídio de Santa Maria ${ }^{15}$, narra o processo de contratação do "piloto e remeiros que devem tripular o [o barco] Rio Vermelho até o Pará, fazendo-os assinar contratos [...], escolhendo-se o piloto mais experimentado e os melhores camaradas" (MORAES, 1995, p. 172 - ênfase no original). Neste trecho aparece o contrato regido pela Lei da Camaradagem, à qual já aludimos, como instrumento de controle. Entretanto, apesar dos rigores dessa lei que, em caso de desobediência dos barqueiros, prevê vinte dias de prisão acrescidos cumulativamente de mais vinte a cada reincidência, não era fácil controlá-los. Mais adiante, o presidente da província, o mais alto representante do poder executivo dessa lei, relata que tendo despertado às três horas da madrugada para partir de Santa Maria, conforme contrato firmado com os barqueiros, do despertar até às seis horas da manhã percorreu o povoado em busca dos remeiros e então a narrativa segue:

percorro a povoação chamando pelos camaradas; eles aparecem e desaparecem... mas eu os chamo incessantemente. São seis horas da manhã; estamos a bordo do bote, e faltam alguns remeiros; os comandantes do presídio e do vapor afligem-se e pedem-me que espere o almoço; respondo-lhes que daquele momento em diante estou embarcado e só almoçarei a bordo... alguns aparecem... e faltam outros. Às sete horas estão todos presentes, menos o índio 
gavião; mandei que embarcassem, e dei ordem ao piloto e proeiros que pusessem o bote ao largo... (MORAES, 1995, p. 178).

Ainda segundo o relato, o índio gavião, um dos barqueiros/ remeiros, alcançou o 'Rio Vermelho' algum tempo depois em uma canoa, ao que foi admoestado pelo presidente, que aproveitou para dizer a todos que deixaria qualquer um no porto caso não estivesse pronto para zarpar na hora contratada. Podemos inferir das várias reticências grafadas em sua escrita que o presidente queria demonstrar ao leitor que tais aposiopeses representavam suspiros de 'infinita paciência', por meio da qual tentava lidar com a insubordinação dos remeiros. E, pacientemente, ao invés de aplicar os 'rigores da lei', apenas admoestava-os para que a insubordinação não se repetisse, mais uma vez, já que em passagens anteriores deixa claro que episódios assim já haviam ocorrido. Percebe-se aí que, mesmo tendo o poder máximo de 'executar a lei', o presidente preferiu fazer vistas grossas à insubordinação, pois sabia fazer parte da cultura daquelas paragens a negociação com os camaradas que, sabedores de sua imprescindibilidade para a navegação, sentiam-se seguros que não seriam presos, e muito menos deixados para trás, pois se assim ocorresse não haveria outros braços para colocar o bote ao largo.

Independentemente, se o presidente teve paciência ou não, o que foi posto pelos barqueiros naquele momento foi um ritual habilmente encenado de aparecer, desaparecer, entrar e sair do barco, ora uns, ora outros; estratégia pela qual nenhum deles podia ser responsabilizado individualmente, e nem coletivamente. Esse ritual do entra e sai surtiu o efeito esperando, levando, inclusive, tanto o comandante do presídio quanto o do barco, já acostumados a lidar com essas práticas, a aconselharem o presidente a postergar a partida para após o almoço. Aqui, o comandante do barco assume uma postura radicalmente oposta à do piloto que participou 
do episódio narrado por Josias de Almeida que culminou com a morte dos barqueiros embriagados.

Costume, religiosidade, insubordinação e controle estão ligados nesta discussão por meio de uma prática cultural ritualizada em um campo de tensão conflituosa e de negociação em que mesmo os sujeitos com menor poder na arena social, no caso os barqueiros, constituem-se agentes nas relações de força e constroem manobras relativamente eficazes quando se tratava de tensionar os limites da dominação e do controle de seu tempo e de sua sociabilidade. Por outro lado, muitas vezes é na perscrutação desse cotidiano - tratado como constituidor de relações costumeiras descrito e analisado, às vezes em seus menores aspectos, é que podemos encontrar elementos que dão visibilidade a muitos sujeitos esquecidos pela historiografia.

\section{CONSIDERAÇÕES FINAIS}

Pretendemos neste artigo cumprir, ao menos parcialmente, o que consideramos ser uma de nossas responsabilidades sociais enquanto pesquisadores inseridos numa dada região: revelar aspectos da história dessa região que raramente aparecem em outras narrativas historiadoras, ou, mesmo quando aparecem, não são o foco central das análises. Nesse sentido, procuramos aqui revelar elementos de cultura de sujeitos que nas interpretações de uma história tradicional são obscurecidos, tornados quase invisíveis na historiografia. Opacizados como se fossem sombras desencarnadas, fantasmas espectrais dos interesses econômicos dos regatões e ou proprietários de embarcações que singravam os sertões entre o norte de Goiás e Belém do Pará; intentamos, pois, revelar que os barqueiros, apesar de representados narrativamente entre a folclorização e a estigmatização, 
são sujeitos construtores da cultura regional e que, portanto, atuavam em suas realidades buscando minorar suas condições de vida.

Nesse revelar, cremos ter (re)apresentado tais sujeitos enquanto portadores de uma potencialidade de ação à medida que, apesar dos mecanismos de controle impostos sobre eles, como a Lei da Camaradagem, por exemplo, souberam elaborar estratégias, valendo-se dos costumes, dos arranjos culturais, em um navegar no qual exploração e dominação, e a luta, raramente aberta e, o mais das vezes, velada contra ambas, eram mobilizados para transmitir uma mensagem direta: não abrimos mão de nossa dignidade humana, recusamos, ademais, a imposição de um ordenamento cultural sobre nossas vidas e, por isso nos atrasamos, comemos os biscoitos do patrão e exigimos alguns alimentos que são importantes para nosso sustento. Um navegar que, além de fazer circular produtos e mercadorias, transportava gente, suas histórias e seus e costumes.

Também acreditamos ter evidenciado que, subjacentes às representações construídas sobre os barqueiros e sobre a navegação pela cultura letrada, emergem os sentidos simbólicos construídos nas e pelas relações sociais travadas nos rios Tocantins e Araguaia. Nesse sentido, as representações elaboradas por Ayres da Silva, por exemplo, foram tratadas aqui como reveladoras de uma interpretação, em escala reduzida, mas representativa, das relações entre abastados e pobres no sertão do norte de Goiás, reveladas pelas disputas cotidianas, espaço no qual os sertanejos pobres, assim como os barqueiros, evidenciam uma maior mobilidade e desenvoltura, apesar das hierarquias sociais e espaciais dentro e fora dos barcos.

Trouxemos à tona que disputas e tensões em torno da alimentação, deserções, murmurações, tramas, vinganças, greves e rituais, estes últimos vinculados às tradições religiosas ou como encenações orquestradas, eram expressão de elementos de revolta, mas de uma revolta 
negociada permanentemente. Emergiu, também, em nossa interpretação, que a sensação de desconforto dos narradores da história dos barqueiros, que em regra foram ou estavam na condição de seus patrões, era provocada pela percepção de que os barqueiros podiam construir, pela força ou pela negociação, ou, ainda, pela inércia, espaços de luta a partir dos quais buscavam permanentemente alargar suas condições de resistência. Diferentemente das intenções das narrativas, lidas neste trabalho a 'contrapelo', foi possível afirmar que os objetivos dos barqueiros não eram impedir as viagens, muito menos não embarcar, mas demarcar que tinham algum poder de barganha perante as imposições a que eram submetidos, seja pela força, seja pela legislação. Seu objetivo principal era, portanto, viver suas vidas, de acordo com seus interesses e com os seus costumes e sua cultura.

NotAs

(Endnotes)

1 O Estado do Tocantins foi criado somente em 1988. No período de que trata este artigo o território do referido Estado constituía o então norte de Goiás.

2 Bacia Hidrográfica dos Rios Tocantins-Araguaia - É a maior bacia localizada inteiramente em território brasileiro, com $813.674,1 \mathrm{~km}^{2}$. Seus principais rios são o Tocantins e o Araguaia. O rio Tocantins, com $2.640 \mathrm{~km}$ de extensão, nasce em Goiás e desemboca na foz do Amazonas. Possui $2.200 \mathrm{~km}$ navegáveis (Entre as cidades de Peixe-GO e Belém-PA) e parte de seu potencial hidrelétrico é aproveitado pela usina de Tucuruí, no Pará. O Rio Araguaia nasce em Mato Grosso, na fronteira com Goiás (próximo à cidade de MineirosGO) e une-se ao Tocantins no extremo-sul do Pará, mais especificamente na cidade de São João do Araguaia.

3 O termo 'barqueiro' é utilizado, às vezes, para designar apenas o proprietário do barco, geralmente um comerciante. Entretanto, é usado corriqueiramente para se referir aos membros da tripulação constituída de pilotos, proeiros, e remeiros, e é neste ultimo sentido que o utilizamos, salvo quando houver indicação em contrário no texto.

4 Lei na íntegra em Cadernos de Notas e Anexos, anexo 2, de SILVA, Ana Lúcia da. $A$ Revolução de 30 em Goiás. Goiânia: Cânone Editorial e Agepel, 2001.

5 Nascido em 1915 em Minas Gerais. Ainda criança se mudou com seus pais para o 'mato grosso goiano' - região da cidade de Anápolis-GO -, zona de matas ainda fechadas, onde viveu até 1945, trabalhando de agregado em terras alheias. A partir de 1945 mudou-se

Hist. R., Goiânia, v. 19, n. 3, 2014 
para a cidade, começando, instintivamente e ao acaso, a escrever para jornais. Perseguido pela Ditadura Militar em função de seus escritos jornalísticos, foi vítima de vários IPM's -Inquérito Policial Militar - durante o ano de 1965. Refugiou-se no norte de Goiás, passando ainda pelo sul do Maranhão e sul do Pará. Escritor arquivista dessas andanças, colheu inspiração e material para escrever o livro Perpetinha: um drama nos babaçu (1991), no qual relata experiências entre barqueiros, quebradeiras de coco babaçu e castanheiros.

6 Advogado e político, assumiu o cargo de Presidente da Província de Goiás no ano de 1881, no qual ficou até o ano de 1882, quando empreendeu viagem em bote a remos de Santa Leopoldina - atual cidade de Aruanã-GO - pelo rio Araguaia e, adentrado o rio Tocantins, chegou a Belém do Pará, de onde seguiu de navio para o Rio de Janeiro.

7 Nascido em Palma, norte de Goiás, em 1820 tornou-se Juiz Municipal da Vila Carolina, que, neste período, tinha seu território pertencente ainda a Goiás. Filho do Des. Joaquim Teotônio Segurado, ocupou diversos cargos públicos, dentre eles deputado provincial e juiz de direito. No ano de 1847 organizou uma viagem cujo objetivo era testar as possibilidades da navegação comercial pelos rios Araguaia e Tocantins, e dessa viagem resultou o relato Viagem pelos Rios Araguaia e Tocantins, publicado na Revista Trimestral de História e Geografia do IHGB e reproduzido no livro Consciência da Liberdade e outros Temas, de Mário Martins.

8 Nascido na virada do século XIX para o XX. Josias de Almeida foi um regatão (comerciante proprietário de Barco). Iniciou sua atividade de regatão aos dezoito anos de Idade. Seu livro "Do Araguaya ás Indias Inglezas" publicado em 1935 foi escrito com base em suas anotações de viagens realizadas entre 1912 e 1914 quando comprava e transportava o Caucho (Latex) do interior de Goiás para comercializar em Belém-PA. Escreveu ainda o livro "Brasil Real e Sonhado".

9 Comerciantes proprietários das embarcações.

10 Esse costume também era verificado nos momentos de conflitos armados, corriqueiros na região durante o século XIX e décadas iniciais do XX, momento em que os coronéis armavam seus agregados e jagunços para as batalhas nas quais o restilo - cachaça - com pólvora estava sempre presente com o objetivo de 'dar coragem' aos homens.

11 Frei José Maria Audrin nasceu no sul da França em 1879. Ingressando na Ordem Dominicana em 1896, veio como missionário para o Brasil em 1902 e em 1904 transferiu-se para os sertões goiano e paraense com o objetivo de evangelizar os sertanejos e os índios. Trabalhou em Conceição do Araguaia até 1921, quando se transferiu para a cidade de Porto Nacional, no norte de Goiás, permanecendo aí até 1928. Em 1929, retornou a Conceição do Araguaia onde trabalhou principalmente na catequização dos índios Caiapós. Em 1938, retira-se do sertão, indo residir em Uberaba-MG, quando começa a escrever a biografia de Dom Domingos Carrerot denominada Entre Sertanejos e Índios do Norte (1947). Entre 1947 e 1951 escreve suas memórias: Sertanejos que eu conheci, publicada em 1963. Em suas memórias faz uma apresentação minuciosa das relações e das pessoas com as quais conviveu no período em que esteve na região dos vales do rio Araguaia e Tocantins (1904-1938). Estas 
duas obras são referência para o conhecimento etnográfico e para a pesquisa histórica sobre os barqueiros e sertanejos.

12 Tendo sido nomeado Presidente da Província de Goiás e exercido o cargo entre janeiro e dezembro de 1881, Joaquim de Almeida Leite Moraes, por força desse exercício, realizou uma longa viagem de São Paulo à Capital de Goiás, desta a Belém do Pará e do Pará a São Paulo. Dessa Viagem, feita quase toda pelos rios Araguaia e Tocantins, resultou o relato Apontamentos de Viagem, publicado pela primeira vez em 1882 e reeditado com apresentação de Antonio Candido em 1995.

13 Presídio Militar de Santa Maria do Araguaia fundado em 1812 e destruído em 1813 por uma aliança dos índios Xerentes, Xavantes e Carajás, porém reconstruído em 1850, desativado em 1852, reativado em 1859 e destruído mais uma vez em 1860 pelos índios Caiapós e Carajás. Foi reconstruído e reativado definitivamente em 1861. Foi considerado um dos mais importantes presídios militares da região no século XIX para o desenvolvimento da navegação e era localizado às margens do Araguaia. Deu origem à atual cidade de Araguacema-To.

\section{REFERÊNCIAS BIBLIOGRÁFICAS}

ALMEIDA, Josias de. Do Araguaia às Índias Inglesas. Coleção Viagens, Vol. IX. São Paulo: Companhia Editora Nacional. 1935.

AUDRIN, José Maria. Entre Sertanejos e Índios do Norte. Rio de Janeiro: Edições Pugil Limitada; Livraria AGIR Editora, 1947.

AYRES, Joaquim. Navegação do Araguaia. Revista Informação Goyana. Rio de Janeiro. Ano VIII, vol. 8, n. 2. Setembro/1925.

BERNARDES, Carmo. Perpetinha: um drama nos babaçuais. Goiânia: UFG, 1991.

BORGES, Durval Rosa. Rio Araguaia: corpo e alma. São Paulo: IBRASA; São Paulo: USP, 1987.

COUDREAU, Henri. Viagem à Itaboca e ao Itacaiúnas. Tradução de Eugênio Amado. Belo Horizonte: Itatiaia; São Paulo: USP, 1980.

DOLES, Dalísia E. M. As comunicações fluviais pelo Tocantins e Araguaia no século XIX. Goiânia: Oriente, 1973. 
HALL, Stuart. Da diáspora: identidades e mediações culturais. Tradução de Adelaide La Guardia Resende et all. SOVIK, Liv (Org.). Belo Horizonte: UFMG, 2008.

LEITE MORAES, Joaquim de Almeida. Apontamentos de Viagem. CANDIDO, Antonio (Org.). Col. Retratos do Brasil. São Paulo: Cia das Letras, 1995.

NEVES, Zanoni. Os remeiros do São Francisco na literatura. Revista de Antropologia. São Paulo. Vol. 46, n. 1, p. 155-210, 2003.

OLIVEIRA, Maria de Fátima. Portos do Sertão: cidades ribeirinhas do Rio Tocantins. Goiânia: PUC-Goiás, 2010.

SEGURADO, Rufino. Teotônio. Viagem pelos Rios Araguaia e Tocantins, nos anos de 1847 e 1848. In: MARTINS, Mário Ribeiro. Consciência da Liberdade e outros Temas. Goiânia: Kelps, 2008, p. 416-461.

SILVA, Ana Lúcia da. A Revolução de 30 em Goiás. Goiânia: Cânone Editorial e Agepel, 2001.

SILVA, Francisco Ayres. Caminhos de Outrora: diário de viagens (1920-1928). Ed. póstuma. Goiânia: Oriente, 1972.

.Viação fluvial a vapor Tocantins / Araguaya. Revista Informação Goyana. Rio de Janeiro. Ano IX, vol. 9, n. 1, p. 04, agosto/1925. 
